\title{
Digital Twins as a New Paradigm of an Industrial Enterprise
}

\author{
Tatyana Golovina ${ }^{1,}{ }^{*}$, Andrey Polyanin ${ }^{1}$, Alexander Adamenko², Elena Khegay ${ }^{3}$, Vladimir \\ Schepinin ${ }^{4}$ \\ ${ }^{1}$ Department of Management and Public Administration Central Russian Institute of Management, Branch \\ of RANEPA Orel, 302028, Russia \\ ${ }^{2}$ Department of Accounting Theory, Federal State Budgetary Educational Institution of Higher Education \\ (Kuban State Agrarian University named after I.T. Trubilin), Krasnodar, 350044, Russia \\ ${ }^{3}$ Department of Management, Far Eastern Federal University, Vladivostok, 690922, Russia \\ ${ }^{4}$ Peter the Great St. Petersburg Polytechnic University, St. Petersburg, 195251, Russia
}

\begin{abstract}
The aim of this research is to investigate the core principles and possibilities of using digital twin technology for the development of Russia's industrial sectors, taking into account the international experience. Theoretical and methodological research has been based on the scientific works of domestic and foreign scientists on the use of digital technologies in the management of economic systems, including industry. The study was based on a set of quantitative and qualitative methods, including case analysis and text mining. A semantic analysis of scientific publications and industry literature was conducted to assess the condition of the problem field and determine trends in the digital transformation of industries from the standpoint of digital twin technology. In addition, an open-source collection of over 100 case files reflecting the practice of introducing digital twins into production processes was compiled. It has been proven that digital twins provide a wide range of possibilities for production enterprises: increased productivity, efficient use of resources, energy intensity and efficiency, reduction of different kinds of costs at all stages of the product life cycle, production of new types of products, and the modification of the organization's business model. A SWOT analysis of economic entities using digital twins was undertaken, which made it possible to identify the opportunities and threats of their introduction into the production process. The study results have refined the model of a new generation industrial economic system based on the functionality of a digital twin, including the parameters of system and predictive analytics, as well as the Internet of Things platform.
\end{abstract}

Keywords: Digital technology; Industry; Industry 4.0; Management; Virtual production concept

\section{Introduction}

The manufacturing sector plays an important role in the economic development of countries. Industries are constantly developing, new technologies are being created, and processes to improve the quality of products are becoming more complex. The difficult economic situation currently prevailing in the world is leading to the validation of all promising technologies, primarily digital technologies, and in that connection, the industrial paradigm is changing. The previously predicted dynamics of the development and adaptation of digital technologies to production processes are difficult to achieve. It is worth noting that the impact of a complex epidemiological and economic situation on the

*Corresponding author's email: golovina_t78@mail.ru, Tel.: +7-919-263-74-92; fax: +7-486-243-34-19 doi: 10.14716/ijtech.v11i6.4427 
development of specific technologies is not always negative. Under the new reality, a higher rate of development is attainable for certain groups. The technological trends of each digital technology are determined by the external conditions of their development, as well as by scientific, technological, and economic vectors. In conjunction, it is they who determine the technological development dynamics and direction of industries and the national economy as a whole.

In recent decades, the development of information and communication technologies and the resultant digitization of industry have brought significant changes in existing business models and products, making them digital and revolutionary, bringing benefits to the entire value chain, including the end-users of the products. Scientific and technological developments and increasing consumer demand for products with higher sophistication, improved quality, and lower costs have led to a broad debate on a new model for the development of industrial economies. The established practice of using the technological component ensures the formation of fundamentally new, highly efficient business models. It has already led to a significant transformation of social and economic processes. Among the factors determining the future of the production management system are the innovation cycle of the product, new technologies, and the Fourth Industrial Revolution (Industry 4.0). Additionally, among the main trends in the development of basic sciences, there has been a rise in interdisciplinary research, the emergence of new information processing technologies, and increased competition in the skilled labor market.

Industry 4.0 is a new concept of production systems that includes technologies such as the Internet of Things, Big Data, cyber-physical systems, and intelligent objects. Industry 4.0 will present new challenges and opportunities for researchers and managers in the field of process safety and environmental protection. According to Badri et al. (2018), real-time communication, Big Data, remote sensing, production process control and management, off-line equipment, and interconnectivity will be the main assets in the modern industry. As the Fourth Industrial Revolution becomes the prevailing reality, it will lead to a new paradigm shift that will affect the management of labor protection.

Zezulka et al. (2018) consider the basics of building communication systems for open, safe, secure, almost in real-time, standardized communication interfaces and common architecture challenges that conform to Industry 4.0 principles for future enterprises. Müller et al. (2018) study how Industry 4.0 initiates changes in the business models of manufacturing plants. The results of their research show that Industry 4.0 includes three dimensions, namely, high-quality process digitization, intelligent production, and intercompany collaboration. Reischauer (2018) believes that Industry 4.0 is a revolution that will transform industries. He views the new industrial paradigm as a political innovation discourse in the manufacturing industries aimed at the institutionalizing of innovation systems, covering business, education, and politics. Industry 4.0 is a crucial research subject in the sphere of industrial systems management. Meissner et al. (2017) examine the issues of decentralized production control. They compare different properties of approaches and architectures with the goals of Industry 4.0, draw comparisons of how different architectures fit for Industry 4.0, and speak about the need for the development of tools for Industry 4.0 production management.

In Russia, the leading scientific school that researches the effects of the introduction of digital twins is the school of Auzan-Borovkov (Auzan et al., 2019; Borovkov and Ryabov, 2019). The most interesting are the results of the estimation made by leading scientists of different disciplines about the introduction of digital twins. While Borovkov conducts serious technical and technological studies on the development of digital twins in the hightech industry, Auzan conducts fundamental studies to assess the economic impact of the 
introduction and the effect of digital twins on the added value of businesses and the longterm competitiveness of corporations (Borovkov and Ryabov, 2019; Auzan et al., 2019). A large number of publications on the subject of digital twins now constitute either promotional articles or brief reports on the work being conducted in this field that do not bear scientific specifics (Shpak et al., 2020). At the same time, there are a small number of articles that reflect the possibilities of process modeling in transformers using 3D and 2D models (Tikhonov et al., 2020).

Digital technologies enable new prospects in the management of industrial economic systems. However, at present, there is no clear methodological support for the production organization using the function of a digital twin and its role in the realization of modern business models in various branches of the national economy. Thus, the aim of this study is to develop the concept of industrial systems control based on digital twin technology, taking into account the assessment of the accumulated domestic and foreign experience of using this digital tool.

\section{Methods}

The need to study the problems of the development of industrial systems in digital transformation arises from the globalized crises, which necessitate the search for modern methods, tools, and strategies for the development of economic agents. Research on the problem of the introduction of digital twins is closely related to the identification of possible effects from this introduction. It is essential to distinguish the social, organizational, and economic effects of the introduction of digital twins in connection with the rapid development of information and communication technologies.

The methods of structural and system analyses to assess the development of the Industry 4.0 concept and its impact on the introduction of digital twins into the activities of industrial enterprises are used in this work. The prospects for the digital transformation of sectors of the national economy, as well as the risks and threats that impede this process, are determined based on the content of the matrix and SWOT analysis. The results indicate that the scope of application of digital twins is extensive, including the power industry (Smart Grid), the engineering industry, the mining industry, the oil and gas industry, agriculture, logistics, the food industry, etcetera. The projects related to production management, traffic monitoring, and smart energy systems have gained the most popularity in the Russian market.

The retrospective assessment and text mining of domestic and foreign experiences of digital twin technology research made it possible to propose the author's organizational and managerial model of managing an industrial economic system based on the use of evolutionary methods and machine learning algorithms. The scientific novelty of the research lies in the development of theoretical and methodological aspects of industrial systems management. These are distinguished by their reliance on both the technical and technological components of the digital twin and its organizational and analytical parameters, which make it possible to form an organizational and managerial mechanism to manage the development of production facilities and the subsequent assessment of their effectiveness.

\section{Results and Discussion}

In our opinion, the most significant challenges to the transformation of the informational and communicative nature of the organization and management of modern industrial economies are: 
1. The establishment and active use of smart networks and management systems that at the global level transform the environment in which economic agents conduct economic activities. Thus, the forthcoming of uberized systems of network cooperation between customers and performers has made it possible to launch a fundamentally new model of company management, which provides significant advantages through increased flexibility and self-administration.

2. The formation of a new technological order in the global system of industrial relations, based on the widespread use of automation and the intellectualization of production, including Big Data, the Internet of Things, 3D printing, printed electronics, quantum computing, distributed registers (blockchain), autonomous robots, etcetera. On this basis, the main results of the transition of the socio-economic system to a new technological level are highlighted: the digital transformation of production systems; freeing people from routine; greater transparency of the world; individualization of a human being as the main subject of the world economy; and others.

3. The creation of new production methods and technologies based on additive technologies implies a fundamentally different principle of formation based on layerby-layer production. This approach allows the creation of an unlimited number of options and types of products and ensures zero waste in production. The most eloquent example of additive production is the use of 3D printing technology in production processes.

4. The development and widespread use of artificial intelligence in production processes has changed the way we think about human functions in almost all spheres of human activity. This changes the quality requirements for the workforce and significantly reduces production costs.

5. The digitization of production leads to the blurring of the boundaries between bio, social, and digital reality, which is reflected in the rapid development of the Internet of Things (Iot) technology, which radically transforms the nature of production and economic relations. The prerequisites for the formation of the social status of the creator of consumer values are emerging. Globally dominant technological solutions, including globally oriented digital platforms, have resulted from long-term technological innovations, large domestic markets, and sound public policies.

The basis of the concept of Industry 4.0 is the provision of technologically significant components of production systems: The Internet of Things (IoT) and also the Industrial Internet of Things (Iiot), artificial intelligence, robotics, cloud services, Big Data, and additive production (Marr, 2017; Schwab, 2020). The combination of these elements into a complete cyber-physical system provides new content in industrial policy, as well as the formation of fundamentally new business models based on the use of digital information technologies as a prerequisite for the network cooperation of producers and consumers, operational flexibility, improvement of productivity and economy, etcetera.

Digital twin technology is one of the key technologies for improving the performance of industrial systems. In fact, it is now recognized as a key part of Industry 4.0. This category continues the Continuous Acquisition and Life cycle Support (CALS) and Product Lifecycle Management (PLM) methodologies that emerged in the early 21st century (Balakin and Kersky, 2020; Tsekhla and Simchenko, 2020). A digital twin is a virtual interactive copy of a physical object or process that helps to effectively manage it by optimizing business operations (Berawi, 2014; Ponomarev et al., 2019). The concept of virtual production is embodied in the form of a digital twin. It was from the second half of the 2010s that computing power allowed the real-time creation of almost identical copies of real physical 
objects and processes. Currently, the use of digital twins is considered in industrial production in the following countries: Japan, the UK, Sweden, Finland, Switzerland, France, Germany, and others (Lee et al., 2015; Datta, 2017; Berawi, 2018; Govindaraju et al., 2018; Suryanegara et al., 2019). So far, especially in Russia, digital twins have helped to improve the actual and forward-looking efficiencies of the oil and gas industries and manufacturing sectors, as well as economic actors that produce high-tech products, in particular, the aviation and space industries (Serdyukov, 2020). For example, digital twin technology helped to combine 20 refining and mining enterprises of the oil and gas operator ADNOC into a single control room. Schneider Electric is developing a digital twin at the Yaya Oil Refinery to create a virtual simulator for operators and an operational emergency prevention system. Rosneft has already implemented a similar project and launched its digital field into pilot operation in May 2019 (Pospelova et al., 2020). Industrial digital twins can be used both at the research and advanced development stages, where modeling helps to reduce development time and costs and manage changes at all subsequent stages (Kokorev and Posmakov, 2019). The results obtained indicate that the scope of application of digital twins is vast, including the power industry (Smart Grid), the engineering industry, the mining industry, the oil and gas industry, agriculture, logistics, the food industry, etcetera (Grieves, 2014). Projects related to production management, traffic monitoring, and smart energy systems have gained the most popularity in the Russian market.

Several definitions may become useful to describe the concept of the digital twin:

1) Digital twin technology is a software analogue of a physical object existing in the real world, modeling the internal processes, technical characteristics, and behavior of the object under certain conditions.

2) A digital twin is a dynamic digital model of an industrial facility that makes it possible to better predict the efficiency of the equipment and business.

3) A digital twin is a virtual model that integrates all information about a specific object, modeling the internal processes, technical characteristics, and behavior of the real object. Throughout the life cycle of an object, a digital twin accumulates data rather than being limited to the set of data it contains at the stage of development and manufacture.

A digital twin is also called a digital counterpart, which is an exact copy of the real object but is modeled by a program. Therefore, a digital twin consists of three components: physical objects in the physical world, virtual models of the virtual world, and combined data that bind the two worlds (Hehenberger and Bradley, 2016). Virtual models update themselves with data from the physical world to account for changes. In this way, problems are quickly detected, and an optimal solution is developed by simulating in the virtual world. According to the authors, an important feature of the digital twin is that the model created with this technology reflects the features of the object as closely as possible, which allows simulating different situations, experimenting with the model, and checking the functionality of the object without using the real device. This helps to significantly accelerate and reduce the cost of testing, since the environmental conditions can be created virtually rather than physically.

While it is useful to implement digital twin technology in the development of high-tech industries, the impact of new solutions on the economy is still relatively small in terms of long-term development effects. At present, digital twin technology is often identified within the category of generative design (Tikhonov et al., 2020). According to the authors, generative design is the next stage of the development of CAD/CAE systems, which focuses on the search for the optimal shape or design of the project product according to its working 
conditions. In a general sense, generative design is an extension of the idea of topological optimization, which makes it possible to find new design solutions at the stage of designing technical devices. It should be noted that ideas of generative design are currently being pursued mainly in the field of machine building (Parshina and Frolov, 2020). Scientific works in the field of the generative design of electrical machines and transformers are not yet available. Since generative design results in some conditions for the creation of new performances of the project device, which are not covered by proven methods of engineering calculation, this technology is closely related to another characteristic direction of economic development related to the concept of digital twins.

Digital twin technology makes it possible to estimate the results of design solutions without needing to create prototypes, which significantly reduces the material costs of the design, especially for single-piece production or small-volume manufacturing. In this case, CAE technologies working with 3D models, such as ANSYS, CADFEM, and COMSOL, are usually used (Makarov et al., 2019; Bykova et al., 2020). The main problem in industrial system management that arises with this approach is the impossibility of acquiring a commercial license to use the expensive technology platform's data. From the perspective of effective management, a significant problem is also the training of qualified personnel able to work with these platforms (Govindaraju et al., 2018).

The new paradigm of industrial economic system management based on digital twin technology implies the development of business models such as:

- "Regulatory control"-compliance with the requirements of various regulatory organizations;

- "Preventive control"-monitoring and timely identification of online prerequisites for emergency situations and/or underperformance of equipment;

- "Control of operations"-control of the chain of technological operations, displacement of devices, assessment of equipment load, integration on a single digital platform of production facilities of geographically distributed production and logistics systems;

- "Automation of operations" - collection and processing of Big Data with the help of SMART devices in use;

- "Sales of functionality" in the equipment operation, which consists of the assignment of equipment for use (without providing the ownership of it), payment is made upon the fact of using its functions or upon the effective time of use;

- "Intelligent model of energy capacities reservation" is a digital asset strapping that provides the opportunity for optimal planning of the utilization of generating capacities. The model of the new generation industrial economic system, which is based on the functionality of a digital twin, is shown in Figure 1.

Thus, digital twins can be created not only to control any mechanism or technological process, but digital "clones" can also be created for an entire enterprise along with all its business processes. The digital twin of an enterprise can comprise the processes of the entire organization, starting from the purchase of goods for production up to logistics and services. It includes all data on the technological processes, the effectiveness of quality management methods, and the planning of subsequent operations in production (Saddik, 2018; Averyanov et al., 2019). According to the authors, digital twin technology provides a huge number of opportunities to simulate a variety of situations that may occur in production, up to critical ones, without putting production itself at risk. 


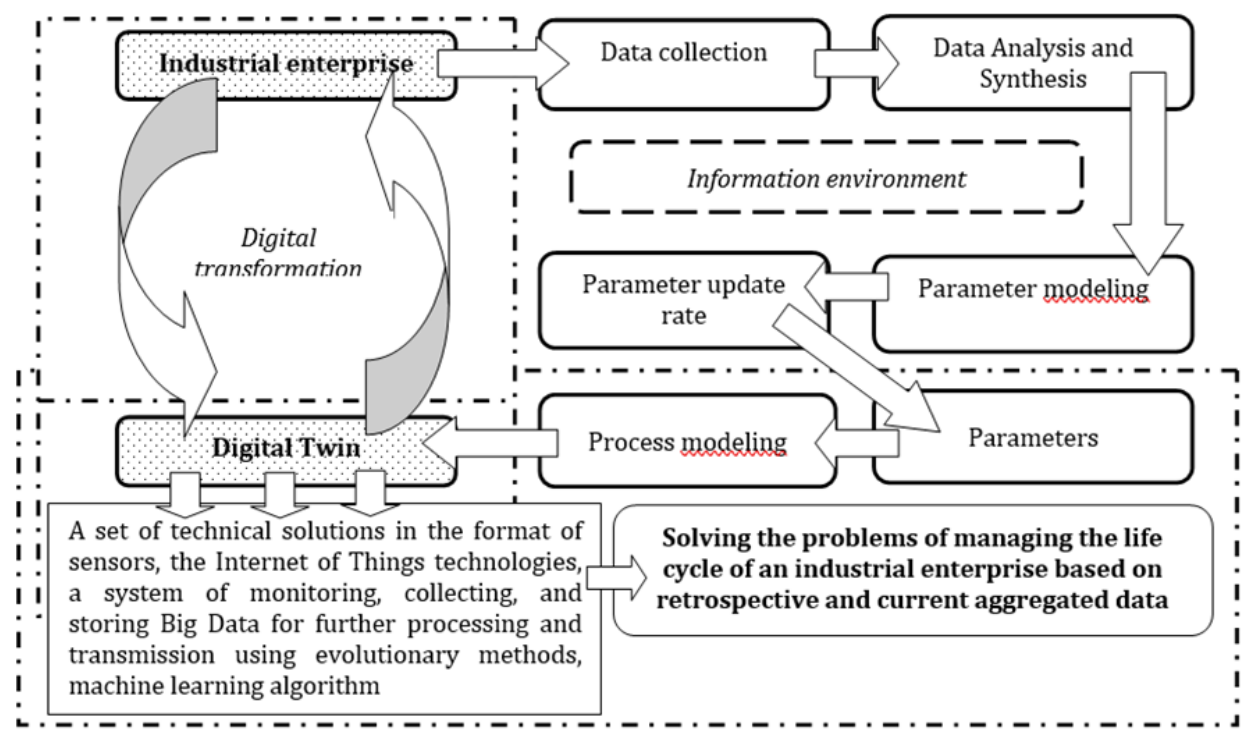

Figure 1 The model of the new generation industrial economic system

According to the authors, the paradigm of industrial system management in the era of digital transformation is formed on the content of the digital twin, which includes the parameters of system and predictive analytics, as well as the IoT platform (Figure 2).

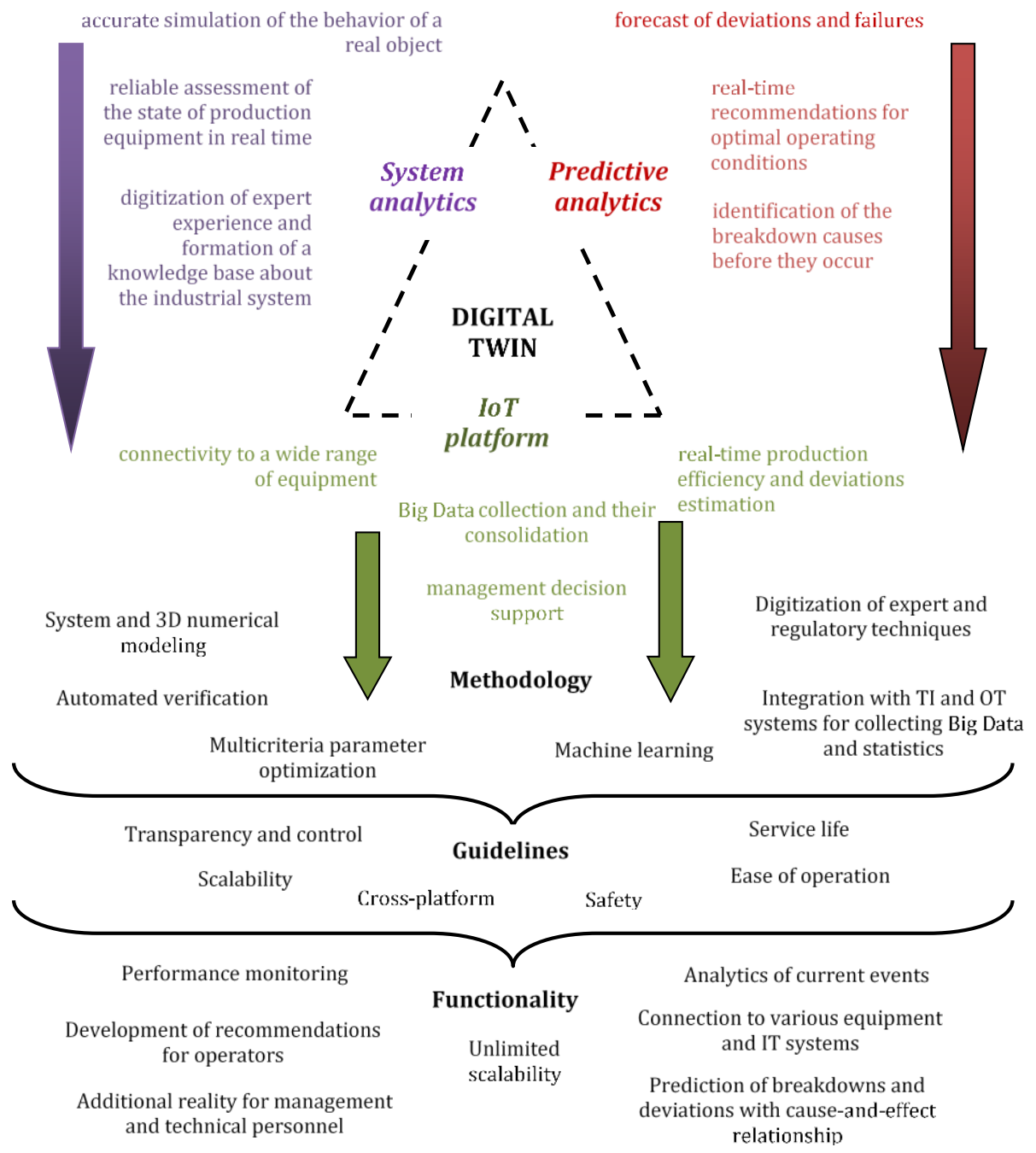

Figure 2 The trimodal concept of industrial system management based on digital twin technology 
Let us consider in more detail the functions of a digital twin:

1. Improving the efficiency of enterprise processes: The system simulates production and the technological process in such a way that the time of useless actions is reduced and clear obligatory production steps for the technological process are performed; the system also makes it possible to rebuild processes in the production chain so that a continuous work flow is ensured.

2. Cost reduction while developing a new product: In most industries, each order is a small-scale production that takes into account the wishes of the customer; therefore, the ability to flexibly and quickly adapt to the requirements of the technical task is the right way for the enterprise to reach financial success.

3. Diagnostics of equipment during operation: The digital twin system selects the optimal operating conditions of the equipment and technological process scenarios and, equally important, predicts deviations in the equipment's operation based on information obtained from statistical models and engineering analysis.

An important issue for industrial economic systems is the use of digital twin technology in such a way as to ensure openness to stakeholders and to maintain staff welfare. It is advisable to be guided by basic principles that would allow manufacturing companies deploying this technology to ensure transparency.

\section{Conclusions}

A digital twin is a virtual "layout" (prototype) of a real object or a group of objects of a technological process in industrial economic systems. The creation of digital twins ensures the rapid production and delivery of products with competitive properties in the context of global high-tech competition.

Using, to one degree or another, certain basic technologies of production digitalization, companies create their digital twins in the form of global platforms for modeling, simulation, and analysis of their production systems. Nevertheless, industrial enterprises wishing to realize the transition to a digital production model must identify, evaluate, and form new essential competencies, adapt their existing business strategies, and develop new ones as part of the implementation of the Industry 4.0 concept. The implementation of such a transformation requires the active application of a systematic approach in planning and evaluation, as well as a solution to the security and digital protection issues, the standardization processes, training and professional development, and the technological base.

Digital twins, as a new paradigm, can change the role of traditional production processes by changing the way the production is realized. Digital twin technology allows the realization of the transition to intelligent manufacturing technologies and the formation of Big Data processing systems. It helps to solve several complex technical industry problems. The use of digital twins, as well as the formation of a modern production infrastructure on their basis, will make it possible to ensure the optimal volume of production of more high-tech and science-intensive products that can most fully satisfy consumer needs. The prospect of technology development is the use of machine learning methods using neural networks, the development of online monitoring systems, and, as a whole, the formation of a self-learning intelligent digital model of an object to perform highly accurate predictive assessments and implement a multi-option design, taking into account various restrictions. 


\section{Acknowledgements}

This research was supported by the Academic Excellence Project 5-100 proposed by Peter the Great St. Petersburg Polytechnic University.

\section{References}

Auzan, A.A., Komissarov, A.G., Bakhtigaraeva, A.I., 2019. Sociocultural Limitations of the Commercialization of Innovations in Russia. Economic Policy, Volume 14(4), pp. 76-95

Averyanov, A.A., Mikryukov, M.I., Rogova, I.N., 2019. Advantages of using an Integrated System of an Intelligent Digital Double of an Enterprise in the Operational and Strategic Management of Business Entities. Journal of Legal and Economic Research, Volume 2, pp. $122-125$

Badri, A., Trudel, B., Souissi, A., 2018. Occupational Health and Safety in the Industry 4.0 Era: A Cause for Major Concern? Safety Science, Volume 109, pp. 403-411

Balakin, D.A., Kersky, E.V., 2020. Development of a Digital Twin of the Early Warning Radar. Journal of "Almaz-Antey" Air and Defense Corporation, Volume 1, pp. 10-18

Berawi, M.A., 2014. Modeling and Simulation in Engineering Design and Technology: Improving Project/Product Performance. International Journal of Technology, Volume 4(2), pp. $100-101$

Berawi, M.A., 2018. The Fourth Industrial Revolution: Managing Technology Development for Competitiveness. International Journal of Technology, Volume 9(1), pp. 1-4

Borovkov, A.I., Ryabov Yu A., 2019. Digital Doubles: Definition, Approaches and Development Methods. In: The Collection: Digital Transformation of the Economy and Industry. Proceedings of the Scientific-Practical Conference with Foreign Participation, pp. 234-245

Bykova, V.N., Kim, E., Gadzhialiev, M.R., Musienko, V.O., Orudzhev, A.O., Turovskaya, E.A., 2020. The Use of the Digital Double in the Oil and Gas Industry. Actual Problems of Oil and Gas, Volume 1(28), pp. 8-12

Datta, S., 2017. Emergence of Digital Twins - Is This the March of Reason? Journal of Innovation Management, Volume 5(3), pp. 14-33

Govindaraju, R., Dwipayana, I.N.G.K., Salamah, S.Y., 2018. IT Governance and ERP PostImplementation: Analysing the Impact of IT Business Alignment and IT Benefits Management on ERP Operation and Enhancement. International Journal of Technology, Volume 9(3), pp. 578-588

Grieves, M.W., 2014. Digital Twin: Manufacturing Excellence through Virtual Factory Replication, LLC Publication, pp. 1-7. Available Online at https://web.archive.org/web/20170517031855/http://innovate.fit.edu/plm/docum ents/doc_mgr/912/1411.0_Digital_Twin_White_Paper_Dr_Grieves.pdf, Accessed on October, 2020

Hehenberger, P., Bradley, D., 2016. Digital Twin-The Simulation Aspect. In: Mechatronic Futures: Challenges and Solutions for Mechatronic Systems and Their Designers, Hehenberger, P., (ed.), Springer International Publishing, New York, USA, pp. 59-74

Kokorev, D.S., Posmakov, N.P., 2019. The Use of "Digital Doubles" in Production Processes. Colloquium Journal, Volume 26-2(50), pp. 68-74

Lee, J., Bagheri, B., Kao, H.A., 2015. A Cyber-Physical Systems Architecture for Industry 4.0Based Manufacturing Systems. Manufacturing Letters, Volume 3, pp. 18-23

Makarov, V.L., Bakhtizin, A.R., Beklaryan, G.L., 2019. Developing Digital Twins for Production Enterprises. Business Informatics, Volume, 13(4), pp. 7-16 
Marr, B., 2017. What Is Digital Twin Technology-And Why Is It So Important? Available Online at http://www.forbes.com/sites/bernardmarr/2017/03/06/what-is-digitaltwin-technology-and-why-is-it-so-important/\#277a78772e2a, Accessed on October, 2020

Meissner, H., Ilsen, R., Aurich, J., 2017. Analysis of Control Architectures in the Context of Industry 4.0. Procedia CIRP, Volume 62, pp. 165-169

Müller, J., Buliga, O., Voigt, K.-I., 2018. Fortune Favors the Prepared: How SMEs Approach Business Model Innovations in Industry 4.0. Technological Forecasting and Social Change, Volume 132, pp. 2-17

Parshina, I.S., Frolov, E.B., 2020. Development of a Digital Twin of a Production System on the Basis of Modern Digital Technologies. Economics in Industry, Volume 13(1), pp. 2934

Ponomarev, K.S., Feofanov, A.N., Grushina, T.G., 2019. Digital Production Double-A Means of Digitalizing the Organization's Activities. Automation and Modeling in Design and Management, Volume 2(4), pp. 11-17

Pospelova, T.A., Strekalov, A.V., Knyazev, S.M., Kharitonov, A.N., 2020. Implementation of Digital Twins for Gas Field Management. Oil Province, Volume 1(21), pp. 230-242

Reischauer, G., 2018. Industry 4.0 as Policy-Driven Discourse to Institutionalize Innovation Systems in Manufacturing. Technological Forecasting and Social Change, Volume 132, pp. 26-33.

Saddik, A.El., 2018. Digital Twins: The Convergence of Multimedia Technologies. IEEE MultiMedia, Volume 25(2), pp. 87-92

Schwab, K., 2020. The Fourth Industrial Revolution: What It Means and How to Respond. Moscow. Eksmo, p. 208 (Top Business Awards)

Serdyukov, R.D., 2020. Conceptualization of the Concept of "Digital Double" in the Industrial Segment of the Economy. In: The Collection: Digital Economy and Industry 4.0: Foresight Russia. Proceedings of the Scientific-Practical Conference with Foreign Participation. St. Petersburg Polytechnic University of Peter the Great, pp. 250-258

Shpak, P.S., Sycheva, E.G., Merinskaya, E.E., 2020. The Concept of Digital Doubles as a Modern Trend in the Digital Economy. Bulletin of the Omsk University, Series: Economics, Volume 18(1), pp. 57-68

Suryanegara, M., Harwahyu, R., Asvial, M., Setiawan, E.A., Kusrini, E., 2019. Information and Communications Technology (ICT) as the Engine of Innovation in the Co-Evolution Mechanism. International Journal of Technology, Volume 10(7), pp. 1260-1265

Tikhonov, A.I., Stulov, A.V., Snitko, I.S., Similar, A.V., 2020. Development of 2D-Models of the Magnetic Field for the Implementation of Digital Twin Technology and Generative Design of Power Transformers. Bulletin of the Ivanovo State Energy University, Volume 3, pp. 32-43

Tsekhla, S.Yu., Simchenko, N.A., 2020. Methodological Aspects of the Study of the Economic Effects of the Introduction of Digital Doubles in Industry. Bulletin of the South Russian State Technical University (Novocherkassk Polytechnic Institute), Series: Socio-economic Sciences, Volume 13(2), pp. 35-39

Zezulka, F., Marcon, P., Bradac, Z., Arm, J., Benesl, T., Vesely, I., 2018. Communication Systems for Industry 4.0 and the IoT. IFAC-PapersOnLine, Volume 51(6), pp. 150-155 